\title{
Unidades do mapa geológico da ilha de Santa Catarina: as rochas
}

Edison Ramos Tomazzoli*

Joel Marcel Pellerin**

\section{Resumo}

Geologicamente, a Ilha de Santa Catarina é constituída por maciços rochosos formados por migmatitos do Complexo Águas Mornas, por granitos São Pedro de Alcântara e Ilha e por rochas plutonovulcânicas ácidas que compõem a Suíte Cambirela. Esses litotipos são seccionados por diques básicos, ácidos e intermediários que compõem o Enxame Florianópolis e também por rochas cataclásticas e por falhas/fraturas diversas. Interligando esses maciços, ocorrem depósitos quaternários inconsolidados, que constituem a planície costeira, depositados sob condições e ambientes deposicionais variados. Essas unidades estão representadas no mapa geológico da ilha: http://lmo.ufsc.br/mapageologico-da-ilha-de-santa-catarina/.

Palavras-chave: Mapa geológico; Ilha de Santa Catarina; Geocartografia.

** Professor do Departamento de Geociências - CFH/UFSC (Edison@cfh.ufsc.br).

**** Professor do Departamento de Geociências - CFH/UFSC (pellerin@cfh.ufsc.br).

Geosul, Florianópolis, v. 30, n. 60, p 225-247, jul./dez. 2015 
TOMAZZOLI, E.E \& PELLERIN, J.M. Unidades do mapa geológico da ilha...

Geological map units of the Santa Catarina island: the rocks

\begin{abstract}
Geologically, the Santa Catarina island shows massives constituted by Águas Mornas Complex migmatites, São Pedro de Alcântara and Ilha granites and Suite Cambirela plutono-volcanic acid rocks. These lithotypes are cross cutted by basic, intermediate and acid dykes that compound the Florianópolis swarm and by fault/ fractures and cataclastic rocks. There are coastal plain inconsolidate Quaternary deposits between these massives that were deposited in varied sedimentary environments. These units are represented in a geological map: http://lmo.ufsc.br/mapageologico-da-ilha-de-santa-catarina/.
\end{abstract}

Key words: Geological map, Santa Catarina island, Geocartography.

\title{
Introdução
}

A ilha de Santa Catarina (ISC) possui cerca de $395,7 \mathrm{~km}^{2} \mathrm{e}$ está justaposta à porção central da área costeira do estado de Santa Catarina (Fig. 1A).

Neste artigo é apresentada a caracterização das unidades rochosas que compõem o mapa geológico da ISC, cujo acesso/ download do site http://mo.ufsc.br/mapa-geologico-da-ilha-desanta-catarina/ é indispensável para o seu acompanhamento. Esse mapa, embora esteja apresentado na escala 1:50.000, foi elaborado sob base cartográfica em escala 1:2.000 o que, combinado ao elevado grau de detalhamento geológico de suas unidades, torna-o compatível à visualização e impressão em escala 1:10.000.

O referido mapa foi construído com a colaboração de 125 estudantes dos cursos de graduação, mestrado e doutorado em Geografia do Departamento de Geociências da Universidade Federal de Santa Catarina (UFSC), participantes das disciplinas intituladas Prática de Campo em Mapeamento Geológico- 
TOMAZZOLI, E.E \& PELLERIN, J.M. Unidades do mapa geológico da ilha...

Geomorfológico e Técnicas de Mapeamento GeológicoGeomorfológico. Essas disciplinas, oferecidas entre 1998 e 2012, totalizaram 24 semestres ou etapas de mapeamento, cada etapa enfocando determinado setor da ilha, num total de 192 dias de campo. Isso resultou num grande detalhamento do mapa, com cerca de 5.100 pontos-afloramento na área total da ilha.

\section{Caracterização geológica das unidades}

Do ponto de vista geológico-geomorfológico, a ilha de Santa Catarina (Fig. 1B) pode ser dividida em dois domínios fundamentais: a) domínio de morros, montanhas e elevações, constituído por migmatitos do Complexo Águas Mornas, pelos granitos Ilha e Itacorubi e por rochas vulcânicas ácidas da Suíte Cambirela, todos cortados por diques do Enxame Florianópolis; b) domínio das planícies costeiras que interligam essas elevações e são constituídas por depósitos quaternários inconsolidados, de origem variada. Nesse artigo são descritos e caracterizados os litotipos que compõem os maciços da ISC. A caracterização dos depósitos inconsolidados da planície costeira da ilha pode ser obtida em Caruso Jr. (1993), Livi \& Horn Filho (2011) e Horn Filho et al. (2015, no prelo).

\section{Complexo Águas Mornas}

Os litotipos do Complexo Águas Mornas ocorrem, preferencialmente, no morro dos Ingleses, situado entre a praia dos Ingleses e a praia do Santinho e no morro das Aranhas, situado entre a praia do Santinho e a praia do Moçambique, nordeste da ISC. De forma mais restrita, ocorrem também junto à ponta do Sambaqui e na localidade de Costa de Dentro, a norte da enseada do Pântano do Sul. 
TOMAZZOLI, E.E \& PELLERIN, J.M. Unidades do mapa geológico da ilha...

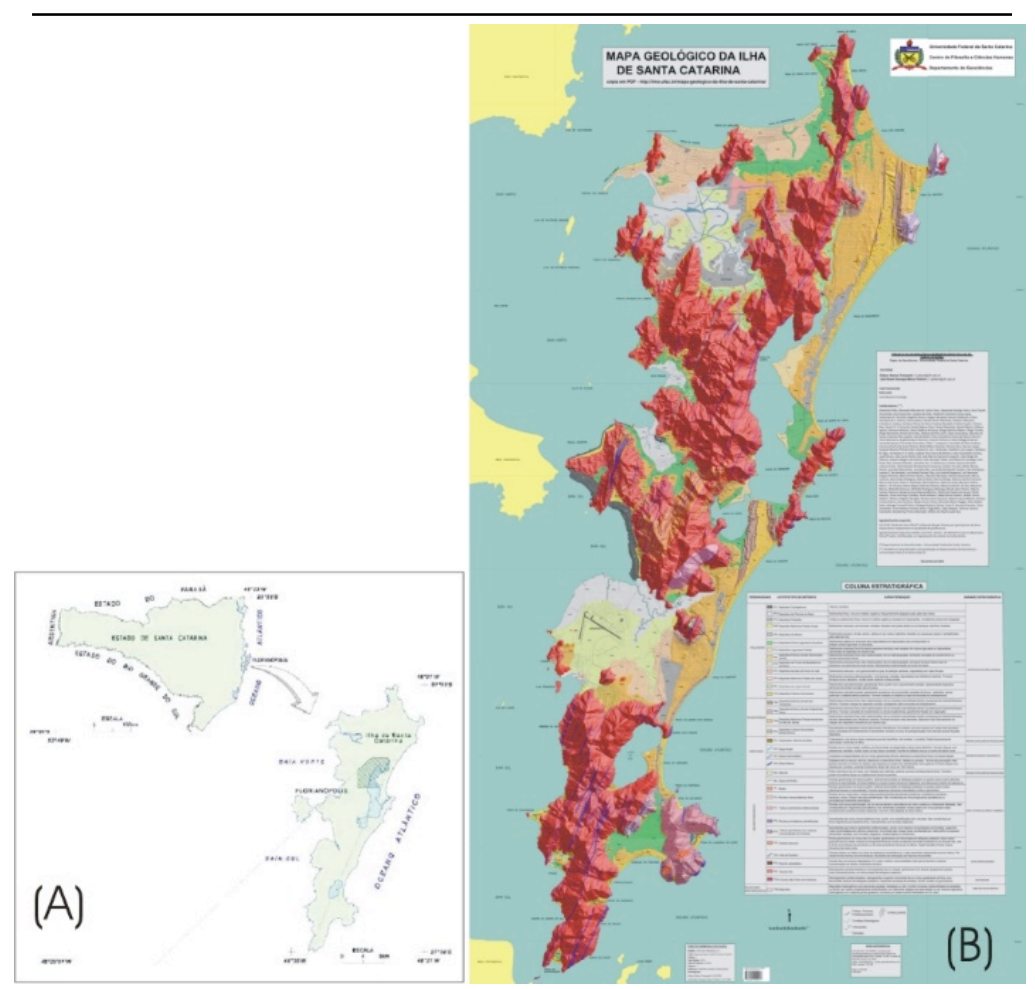

Figura 1 (A): Mapa de localização da ilha de Santa Catarina. (B) Mapa geológico da Ilha de Santa Catarina. (para visualização detalhada, acessar: http://lmo.ufsc.br/mapa-geologico-dailha-de-santa-catarina/).

O complexo é constituído por ortognaisses e migmatitos similares aos descritos por Zanini et al. (1997), cujas datações U$\mathrm{Pb}$ SHRIMP (SILVA et al., 2000) revelaram idade de $2.175 \pm 13 \mathrm{Ma}$ para o protólito e $592 \pm 5 \mathrm{Ma}$ para o metamorfismo/deformação superimpostos. Representam as rochas mais antigas da ilha.

São extremamente heterogêneos, representados, principalmente por corpos máficos parcial ou totalmente 
TOMAZZOLI, E.E \& PELLERIN, J.M. Unidades do mapa geológico da ilha...

anfibolitizados, com dimensões e formatos variados e envoltos por granito-gnaisse milonítico leucocrático médio a grosso, localmente porfirítico, cujo maior ou menor índice colorimétrico reflete o grau de assimilação dessas rochas máficas. Ambos litotipos apresentamse envoltos por remobilizados graníticos, equigranulares finos a médios, de cor rosada, que constituem uma rede de veios e bandas de espessura variada (Figs. 2A e 2B, respectivamente). Essas rochas anfibolitizadas representam restos de uma sequência mais antiga, deformada e metamorfisada, intrudida por rochas graníticas.

Nas zonas de maior deformação (maior stain), essas rochas máficas inclusas nos granito-gnaisses com maior ou menor grau de assimilação podem apresentar deformações dúcteis e transposição para bandas, intercaladas com bandas do remobilizado granítico (Fig. 2C). Nessas zonas é comum, ainda, a presença de faixas de gnaisse milonítico, com espessuras variáveis, exibindo complexos padrões de dobramento (Fig. 2D).

Nas zonas de menor strain podem ocorrer, enxames de enclaves mágicos magmáticos (EMM) maciços e afaníticos (Fig. 2E), eventualmente contendo xenocristais ovóides de feldspato alcalino (Fig. 2F), indicadores de processo de magma mingling (VERNON, 1984, DIDIER \& BARBAIN, 1991). São às vezes alinhados ou alongados, em forma de diques sinplutônicos ou schlieren. A presença de EMMs sugere a injeção de magma básico por diques sinplutônicos na câmara magmática félsica, fragmentados pelo fluxo magmático do hospedeiro (PITCHER, 1991). Deformações tectônicas, durante ou após esse evento, originaram bandamento nas zonas de maior strain.

Embora esses litotipos tenham sido colocados com integrantes da Suíte Paulo Lopes em trabalhos anteriores, optou-se por interpretá-los num sentido mais amplo e colocá-los como membros do Complexo Águas Mornas, como foi feito com sequências semelhantes no município de São José (ZANINI et al., 1997), notadamente na zona rural do Bairro Alto Forquilhas. 
TOMAZZOLI, E.E \& PELLERIN, J.M. Unidades do mapa geológico da ilha...
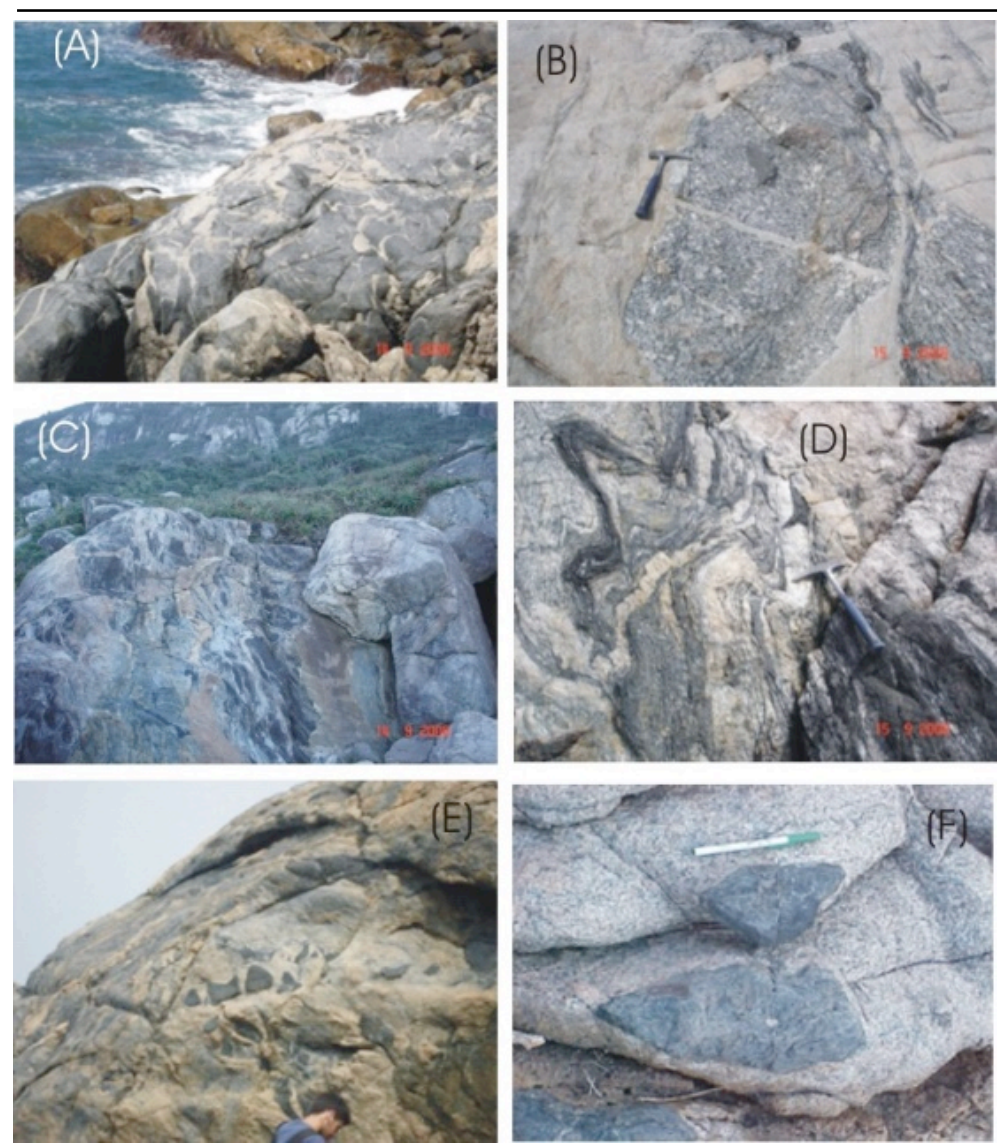

Figura 2: (A) Brechação de anfibolitos por net-veining de remobilizados graníticos rosados. (B) Porção granito-gnáissica granodiorítica porfírica, resultante da assimilação parcial de enclaves máficos, envolta pela rede de veios e bandas graníticas rosadas. (C) Migmatito bandado, com bandas de remobilizado granítico rosado, intercaladas a bandas de anfibolitos parcialmente assimilados. (D) Faixas de gnaisse milonítico bandado, exibindo dobramentos. (E) Enclaves máficos magmáticos (EMMs). (F) 
TOMAZZOLI, E.E \& PELLERIN, J.M. Unidades do mapa geológico da ilha...

Xenocristal ovóide de feldspato alcalino (no centro do EMM inferior), indicando processo de magma mingling.

\section{Granito São Pedro de Alcântara}

Compõe os granitóides calcialcalinos integrantes da Suíte Maruim, intrusiva no Complexo Águas Mornas (ZANINI et al., 1997). Datações pelos métodos Rb-Sr e U-Pb, mostraram idades isocrônicas de, respectivamente, $566 \pm 93 \mathrm{Ma}$ e $600 \pm 7 \mathrm{Ma}$ (BASEI, 1985).

Na ISC, ocorre no sul do Maciço da Costeira, bairro Rio Tavares como granitos mesocráticos de cor cinza, com granulação grossa a média, via de regra exibindo fenocristais esbranquiçados de feldspato potássico e, eventualmente, de plagioclásio. Contém abundantes enclaves de tonalito e quartzo diorito (Fig.3A). Ao microscópio, observa-se feldspato potássico, quartzo, plagioclásio e biotita como constitutivos principais, seguidos por minerais opacos, hornblenda e muscovita em ordem decrescente de abundância. Zircão, esfeno allanita e apatita aparecem como acessórios, enquanto sericita, clorita epidoto e carbonato como minerais secundários.

\section{Granito Ilha}

Corresponde ao Granito Grosseiro Ilha, originalmente definido por Scheibe \& Teixeira (1970). Integra a Suíte Intrusiva Pedras Grandes (ZANINI et al., 1997) que engloba também o Granito Serra do Tabuleiro e outros granitóides alcalinos de natureza pós-tectônica, com muito pouca ou nenhuma deformação dúctil. Datações Rb-Sr acusaram idades de $524 \pm 68 \mathrm{Ma}$ (BASEI, 1985).

Rocha predominante na ISC, apresentam-se como sieno e monzogranitos maciços, isótropos, de coloração rosada ou cinzaclaro, com textura equigranular, mais raramente pórfira, grossa ou média, hipidiomórfica (Figs. 3B e 3C). São constituídos por quartzo, feldspato K e biotita (anfibólio) como minerais essenciais; zircão, alanita, apatita e minerais de óxidos de Fe-Ti (magnetita/ ilmenita) como minerais acessórios e epidoto, sericita/muscovita, 
TOMAZZOLI, E.E \& PELLERIN, J.M. Unidades do mapa geológico da ilha...

clorita, titanita, carbonatos e fluorita como minerais secundários. Diques ou bolsões de pegmatito e aplito são bastante comuns. Via de regra, não exibe enclaves e, em determinados locais, exibe feições cataclásticas. Pode exibir tonalidade escura devido a uma maior concentração em óxidos/hidróxidos de ferro em setores de cataclase mais intensa.
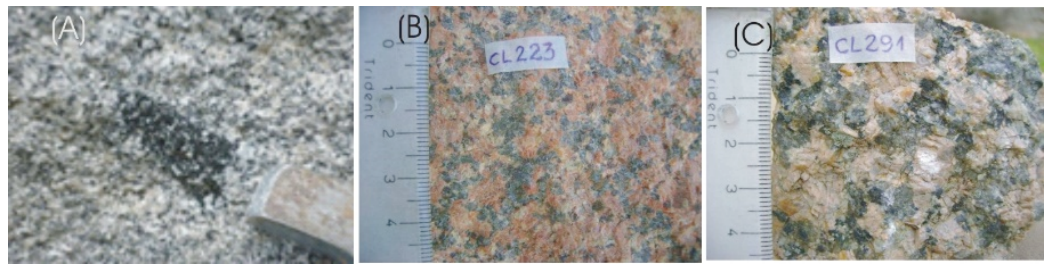

Figura 3: (A) Granito São Pedro de Alcântara, exibindo enclave. (B) Granito Ilha, cor rosada. (C) Granito Ilha, cor cinza-claro.

O Granito Ilha é considerado como uma denominação local correlacionável ao Granito Serra do Tabuleiro, devido à grande semelhança petrográfica e geoquímica entre essas unidades. No morro Cambirela, localizado na área continental imediatamente justaposta à ISC, o Granito Serra do Tabuleiro repousa abaixo de uma superfície que promove seu contato direto com as rochas vulcanoclásticas ácidas da Suíte Plutono-Vulcânica Cambirela, depositadas em ambiente subaéreo (Fig. 4) e que será descrita mais adiante. Portanto, o Granito Ilha é aqui colocado como integrante da Suíte Pedras Grandes, conforme as proposições de Trainini et al. (1978) e Zanini et al. (1997) e não como da Suíte PlutonoVulcânica Cambirela, conforme as proposições de Basei (1985) e Bitencourt et al. (2008).

\section{Suíte Plutono-Vulcânica Cambirela}

A Suíte Plutono-Vulcânica Cambirela é constituída por granito (Granito Itacorubi) diretamente associado a lavas e rochas 
TOMAZZOLI, E.E \& PELLERIN, J.M. Unidades do mapa geológico da ilha...

piroclásticas ácidas (CARUSO JR., 1993; ZANINI et al., 1997). Datações Rb-Sr revelaram idades de $524 \pm 68 \mathrm{Ma}$ AP (BASEI, 1985) para esses litotipos. Rochas hipoabissais, representadas principalmente por diques de riolito, também integram essa unidade.

No morro Cambirela, cerca de $10 \mathrm{~km}$ a oeste da ISC, rochas vulcânicas da Suíte Plutono-Vulcânica Cambirela sobrepõem-se, ao Granito Serra do Tabuleiro, definindo uma superfície que constitui uma das mais espetaculares feições morfotectônicas do PréCambriano do sul do Brasil (Fig. 4). Essa feição está sendo objeto de estudos visando sua indicação como geossítio (PIMENTA, 2015, em elaboração). No local, Zanini et al. (1997) descrevem a ocorrência de xenólitos do Granito Serra do Tabuleiro englobados por rochas vulcânicas, evidenciando que o granito já estava consolidado quando da extrusão. Exames detalhados no local evidenciaram um aglomerado/brecha vulcânica, que repousa sobre o Granito Serra do Tabuleiro, contendo fragmentos de composição variada, inclusive do granito. Geologicamente, essa superfície parece indicar uma discordância entre as duas unidades, com uma consequente dissociação temporal entre as duas que é extensiva também ao Granito Ilha, na ISC, correlacionável àquele granito.

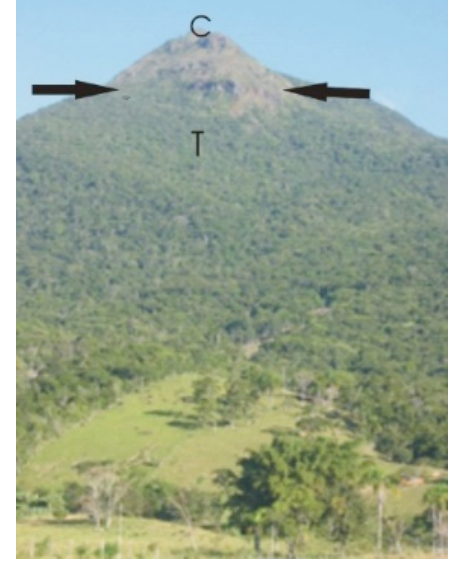


TOMAZZOLI, E.E \& PELLERIN, J.M. Unidades do mapa geológico da ilha...

Figura 4: Foto do morro Cambirela, tomada de nordeste para sudoeste. Setas: superfície de contato entre rochas da Suíte Cambirela e o Granito Ilha. C: Suíte Plutono-Vulcânica Cambirela (acima da Rochas piroclásticas superfície). T: Granito Serra do Tabuleiro (abaixo da superfície).

As rochas piroclásticas ácidas ocorrem principalmente no sul da ilha, no maciço que circunda a praia da Lagoinha do Leste. São constituídas predominantemente por tufos e ignimbritos, com intercalações de lava riolítica.

Os tufos são fortemente litificados, constituídos por cinza fina, cinza grossa e lapili de quartzo ou feldspato em variadas proporções (lapili tufos a cristal) sobre matriz de cor escura, composta por material hemivítreo. Podem conter variadas proporções em bombas e blocos com formatos angulosos, arredondados ou fusiformes, constituídas por material hemivítreo ou por riolito pórfiro, com fenocristais de feldspato alcalino sobre matriz afanítica escura ou avermelhada (Fig. 5A). Estima-se que uma maior concentração nessas bombas implique numa maior proximidade aos centros vulcânicos. Os termos de granulação grossa, via de regra, não exibem nenhuma estruturação, porém as variedades de granulação mais fina podem apresentar estratificação plano-paralela ou ainda estratificação cruzada (Fig. 5B), evidenciando, neste último caso, um transporte lateral. No costão sul da praia da Lagoinha do Leste, observou-se o contato entre essas duas primeiras unidades por escarpa de falha normal com direção NW (Fig. 5C). Com maior frequência, podem apresentar estruturas resultantes de fluxo piroclástico, como as resultantes do estiramento e orientação preferencial de bombas e blocos (Fig. 5D), sendo então classificadas como ignimbritos. Quando intemperizadas, essas rochas adquirem coloração esbranquiçada e os fragmentos de quartzo se destacam em micro relevo. Ao microscópio, exibem shards e porções quartzo-feldspáticas com tamanhos e formas variadas que representam púmices substituídas por esses minerais. Quando o grau de soldagem é maior, mostram textura eutaxítica, com as púmices quartzo-feldspáticas achatadas, 
TOMAZZOLI, E.E \& PELLERIN, J.M. Unidades do mapa geológico da ilha...

constituindo fiames que se amoldam no entorno dos cristais rígidos de quartzo e feldspato.

Em determinados setores, como no costão norte da enseada do Pântano do Sul, constituem rochas vulcanoclásticas de granulação muito fina, de cor clara e com elevada coerência e resistência mecânica. Nesse caso, lembram o sílex, devido a seu aspecto maciço e bordas translúcidas em amostra de mão, podendo ser mais ou menos estratificados (Fig. 5E). Ao microscópio observam-se finos fragmentos epiclásticos e/ou piroclásticos dispostos sobre uma matriz silicosa sob discreta estratificação.
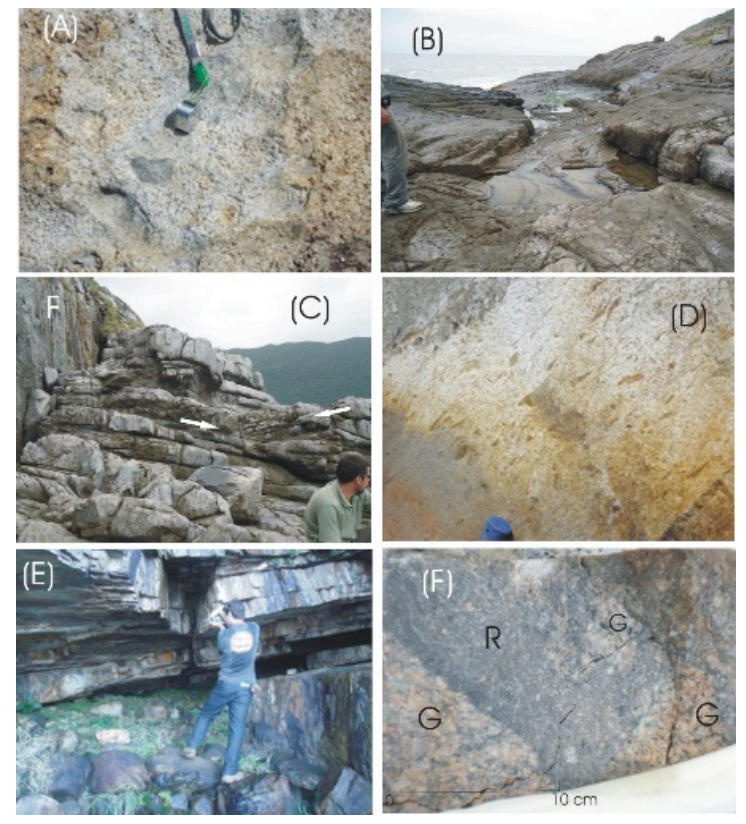

Figura 5: (A) Lapili tufo contendo bombas. (B) Tufos ignimbríticos com estratificação cruzada. (C) Plano de falha vertical, F marca o contato entre tufos ignimbríticos grossos (à esquerda do plano) e tufos mais finos estratificados (à direita), exibindo estratificações cruzadas (setas). (D) Ignimbrito com 
TOMAZZOLI, E.E \& PELLERIN, J.M. Unidades do mapa geológico da ilha...

estrutura de fluxo. (E) Rochas vulcanoclásticas finas, com estratificação inclinada. (F) Amostra do Granito Itacorubi, G xenólitos de granito e R, xenólitos de riolito.

Camadas ou lentes de riolito maciço, com textura pórfira, ocorrem intercaladas às rochas piroclásticas, embora suas dimensões não tenham permitido a representação na escala desse mapeamento.

Os diques de riolito apresentam dimensões variadas, porém raramente ultrapassando a poucos metros de espessura. Podem constituir, também, corpos intrusivos irregulares. Exibem, igualmente, textura pórfira, com fenocristais de feldspato potássico e quartzo facetado sobre matriz afanítica avermelhada ou cinzaclaro.

\section{Granito Itacorubi}

Ocorre associado às rochas piroclásticas, configurando uma faixa semi contínua, com direção nordeste, no maciço que envolve a praia da Lagoinha do Leste. Ocorre também no norte do Maciço da Costeira, bairros Córrego Grande e Itacorubi e no morro da Cruz, área central da cidade, nestes últimos casos, como veios ou corpos intrusivos maiores no Granito Ilha.

Na ISC apresentam-se com sieno ou monzogranitos de cor cinza claro ou rosada, podendo mostrar textura equigranular fina a média, ou ainda textura pórfira, com fenocristais de feldspato potássico ou plagioclásio.

Pode conter xenólitos do riolito que, por sua vez, podem também conter xenólitos do Granito Itacorubi (Fig. 5F), indicando contemporaneidade entre os pulsos magmáticos desses dois litotipos e justificando, assim, a sua colocação numa mesma unidade estratigráfica: a Suíte Plutono-Vulcânica Cambirela, conforme a proposição de Zanini et al. (1997).

\section{Enxame de Diques Florianópolis}


TOMAZZOLI, E.E \& PELLERIN, J.M. Unidades do mapa geológico da ilha...

Teve sua primeira caracterização petrológica de detalhe em Marques (2001). Apresenta uma grande variedade de litotipos, de filiação toleítica, que incluem basaltos do tipo alto-Titânio (ATi) e baixo-Titânio (BTi), andesitos basálticos, traquiandesitos basálticos, andesitos, traquiandesitos e dacitos. Devido a essa variedade de litotipos e, principalmente à ocorrência de rochas ácidas (dacitos) em grande proporção (TOMAZZOLI \& LIMA, 2006), o Enxame de Diques Florianópolis (EDF) diferencia-se em relação aos outros enxames correlacionáveis, como o de Ponta Grossa e o de Santos-Rio de Janeiro e apresenta grande potencial para estudos petrogenéticos relacionados à Província Magmática Paraná-Etendeka como um todo.

$\mathrm{Na}$ ISC, foram mapeados cerca de 400 diques integrantes do enxame. Suas espessuras vão desde centimétricas/métricas, até superiores a duzentos metros, podendo prolongar-se continuamente por vários quilômetros. Estão orientados, preferencialmente, segundo a direção $\mathrm{N} 10^{\circ}-30^{\circ} \mathrm{E}$ e, em menor proporção, segundo N$\mathrm{S}, \mathrm{N} 20^{\circ}-30^{\circ} \mathrm{W}$, e E-W.

Os diabásios ou basaltos ATi são os litotipos largamente predominantes. Podem apresentar textura pórfira (rara), afanítica ou equigranular fina a média. Por vezes ocorrem cordões de xenólitos do granito encaixante, em franco processo de assimilação (Fig. 6A). Termos de granulação grossa ocorrem no centro de diques mais espessos e podem ser classificados como gabro. Predomina a trama intergranular ou subofítica. Seus constitutivos essenciais são plagioclásio, augita, pigeonita e óxidos de Fe-Ti. Em alguns casos, ocorre também olivina. Quartzo intersticial e apatita são os minerais acessórios mais frequentes. Actinolita associada ou não a anfibólio castanho podem ocorrer em pequenas proporções, substituindo piroxênios. Geoquímicamente, são semelhantes aos basaltos ATi do tipo Urubici da Província Magmática Paraná (TOMAZZOLI, 2011; FLORISBAL et al., 2014).

Os termos de BTi são representados por basaltos e traquiandesitos basálticos que geralmente ocorrem com direção NW ou E-W, algumas vezes interceptando diques de basaltos ATi. 
TOMAZZOLI, E.E \& PELLERIN, J.M. Unidades do mapa geológico da ilha...

Podem ser afaníticos, vítreos/hemivítreos, faneríticos finos ou ainda exibir textura pórfira, seriana. São mineralogicamente semelhantes aos basaltos ATi.

Diques de composição intermediária ocorrem no sul da ISC e estão bem expostos no costão sul da praia da Solidão. Podem formar diques simples ou diques compostos (TAYLOR et al., 1980) com bordas de andesito basáltico e núcleo de traquiandesito contendo enxames de enclaves máficos magmáticos (Fig. 6B) do andesito basáltico da borda (TOMAZZOLI \& PELLERIN, 2008). $\mathrm{O}$ traquiandesito é equigranular fino, com microfenocristais de plagioclásio e K-feldspato sobre matriz microgranofírica. Diques compostos desse tipo representam uma evidente interação no estágio magmático entre as rochas do seu núcleo e borda (DIDIER \& BARBARIN, 1991).

Os termos ácidos do enxame são representados principalmente por dacitos e foram caracterizados primeiramente na ilha do Arvoredo (TOMAZZOLI \& LIMA, 2006), setor norte do EDF e depois também no setor norte da ISC (TOMAZZOLI, 2010), onde compõem grandes diques, com direções NNE e NNW, que se estendem de forma semi-contínua por cerca de dez quilômetros. Geoquimicamente são semelhantes às rochas vulcânicas ácidas do tipo Chapecó da Província Magmática Paraná (TOMAZZOLI, 2011). Ao contrário dos demais diques do enxame, tendem a ficar topograficamente ressaltados, configurando expressão positiva de relevo (Fig. 6C).

Os dacitos exibem cor cinza e textura pórfira, com fenocristais tabulares de plagioclásio e pigeonita/augita (menores e mais escassos) sobre matriz granular fina, afanítica, hemi-vítrea ou, granofírica. Plagioclásio, augita, pigeonita, óxidos de Fe-Ti e quartzo são seus constitutivos essenciais, com apatita acessória, e clorita, epidoto, sericita e carbonato como minerais secundários. Eventualmente podem conter anfibólio verde ou castanho substituindo parcialmente a augita.

Geralmente formam diques compostos (TAYLOR et al., 1980), com bordas de basalto ou andesito basáltico ATi e núcleo de 
TOMAZZOLI, E.E \& PELLERIN, J.M. Unidades do mapa geológico da ilha...

dacito (Fig. 6D). A passagem do basalto da borda para o dacito pode ser gradacional ou brusca, neste caso, como resultado de erosão magmática da borda. Enxames de enclaves máficos magmáticos (EMM) da borda são também bastante comuns nos dacitos do núcleo e representam evidências diretas de contemporaneidade e interação no estágio magmático (magma mingling) entre esses dois componentes (DIDIER \& BARBAIN, 1991).
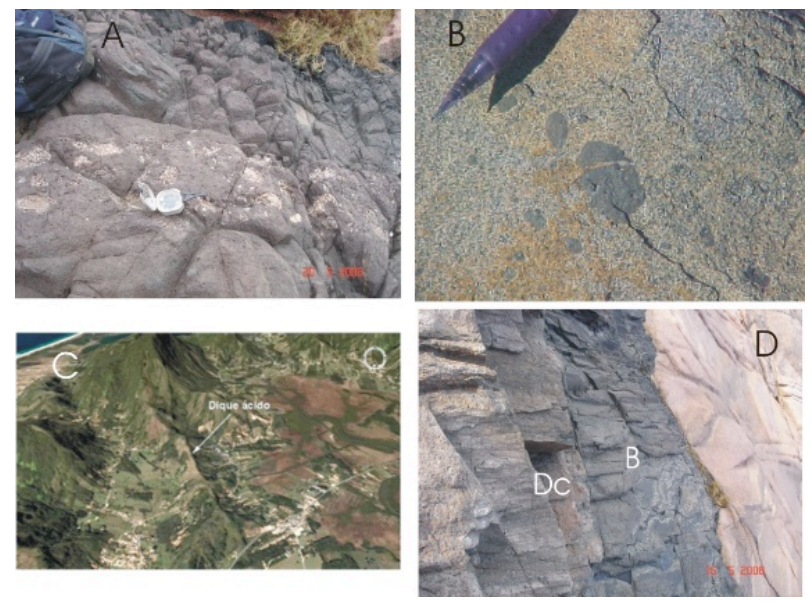

Figura 6: (A) Cordões de xenólitos de granito encaixante, paralelos às bordas do dique. (B) Enclaves máficos-magmáticos da borda de resfriamento inseridos em traquiandesito do núcleo de dique composto. Fonte: Tomazzoli \& Pellerin (2008). (C) Expressão positiva de relevo de dique ácido. Fonte: Tomazzoli \& Pellerin (2008). (D) Dique composto com borda de andesito basáltico registrado em $\mathrm{B}$ e núcleo de dacito $(\mathrm{Dc})$.

Do ponto de vista geocronológico, datações do tipo Ar-Ar em plagioclásio (RAPOSO et al., 1998) mostram uma grande dispersão nas idades para o EDF, que variam entre $119,0 \pm 0,7 \mathrm{e}$ $140,5 \pm 0,5 \mathrm{Ma}$, com duas concentrações principais entre 131-127 e 
TOMAZZOLI, E.E \& PELLERIN, J.M. Unidades do mapa geológico da ilha...

123-121 Ma. Essa dispersão poderia ser oriunda, em parte, a problemas analíticos com esse método de datação. Florisbal et al., (2014), utilizando dados de precisas datações U-Pb em badeleíta e zircão de três diques do setor sul do enxame (municípios de Garopaba e Palhoça) obtiveram idades entre $134.7 \pm 0,3$ e $133.9 \pm 0,7$ $\mathrm{Ma}$, sugerindo que a maior parte dos diques do enxame se posicionou nesse intervalo. Novas datações Ar-Ar stepwise de boa qualidade (TOMAZZOLI, 2011 e TOMAZZOLI et al., em preparação), confirmam, no entanto, os intervalos de idades ente 123 e $121 \mathrm{Ma} ; 134$ e $127 \mathrm{Ma}$, além indicar um terceiro intervalo entre 140 e $137 \mathrm{Ma}$. Isso parece apontar uma origem policíclica para o EDF, como é comum em enxames de diques semelhantes em várias partes do mundo (p.ex., Halls, 1982).

\section{Refusões graníticas}

Em determinados setores da ISC, são evidentes as refusões graníticas, resultantes do aquecimento gerado pelas intrusões de diques do Enxame Florianópolis.

Essas feições são bem claras no costão sul da praia do Saquinho, onde espesso dique de diabásio exibe bordas curvilíneas, irregulares e por vezes transicionais ao riolito encaixante (Fig. 7A), constituído por fenocristais de feldspato potássico sobre matriz afanítica microgranofírica. Essa rocha, por sua vez, exibe numerosos enclaves máficos magmáticos (EMM) do dique (Fig. 7B), indicando processo de magma mingling entre elas.
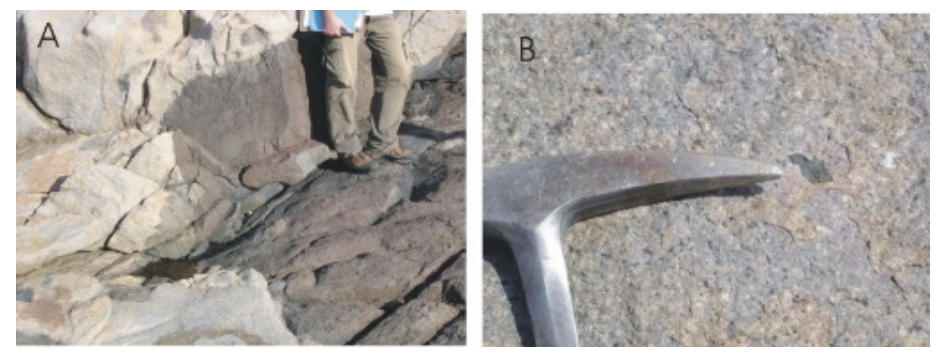
TOMAZZOLI, E.E \& PELLERIN, J.M. Unidades do mapa geológico da ilha...

Figura 7: (A) Contatos irregulares e transicionais entre dique de diabásio (rocha escura) e o riolito encaixante. (B) Enclave máfico magmático (ponta do martelo) do diabásio no riolito encaixante.

Datação Ar-Ar em RT (idade plateau com 49,9\% $\mathrm{Ar}^{39}$ )

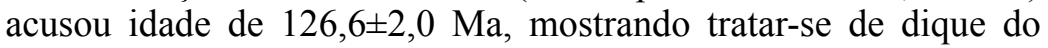
Enxame Florianópolis.

A rocha ácida encaixante, por sua vez, foi datada pelo método U-Pb (ICP MS LA) em zircões. Obteve-se duas idades de concórdia, a primeira (intersepto superior da concórdia) mostrou

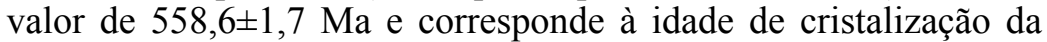
rocha. A segunda (intersepto inferior), foi de 128,76 $\pm 49 \mathrm{Ma}$ (TOMAZZOLI, 2014; TOMAZZOLI, 2015 em preparação) e está relacionada ao processo de perda episódica de $\mathrm{Pb}$ devido ao aquecimento gerado pela intrusão do dique. Conclui-se, portanto, esse dique integra o Enxame Florianópolis e apresenta idade entre $126,6 \pm 2,0$ e $128,76 \pm 49$ Ma. Outra constatação importante é que na rocha ácida encaixante, a textura pórfira típica de um riolito, é, na verdade, produto da refusão de Granito Ilha devido ao aquecimento gerado pela intrusão de dique. Restos desse granito estão parcialmente preservados em pontos mais afastados da intrusão, quando a rocha assume textura equigranular média, típica daquele granito. Por apresentar um padrão textural variável, essa rocha pode ser facilmente confundida com o Granito Itacorubi ou com riolitos da Suíte Cambirela.

No morro da Cruz, área central da ISC, ocorre uma franja de rochas graníticas finas margeando um megadique de diabásio com até 200 metros de espessura. Essa faixa, interpretada nesse trabalho como Granito Itacorubi, poderia, ao invés disso, constituir uma auréola de refusão do Granito Ilha no entorno do dique.

\section{Rochas cataclásticas}

Na ISC, as rochas cataclásticas, bastante minoritárias, são representadas por milonitos, cataclasitos e brechas de falha. 
TOMAZZOLI, E.E \& PELLERIN, J.M. Unidades do mapa geológico da ilha...

Os milonitos podem ocorrer como finas faixas ou zonas de cisalhamento dúctil cortando o Granito Ilha (Fig. 8A), raramente ultrapassando poucos centímetros. Podem exibir bandamento composicional, dado pela alternância de finas bandas micáceas e bandas quartzo feldspáticas. Ocorrem também em faixas ou áreas mais extensas, como na localidade de Costa de Dentro (próximo à enseada do Pântano do Sul), sul da ISC, onde são constituídos por filitos de cor clara (Fig. 8B), compostos por pequenos cristaloclastos oftálmicos de quartzo envoltos por sericita orientada planarmente. São também parte importante do Complexo Águas Mornas, no nordeste da ISC, nesse caso, compondo extensas faixas de gnaisse milonítico, deformadas ou não (Fig. 2D).

Cataclasitos, quase sempre associados às brechas de falha ocorrem, geralmente, em faixas com até poucos metros de espessura e direções N-S e NNE, constituídas por rochas graníticas moídas ou fragmentadas sob condições rígidas, como ocorre na localidade de Ponta das Canas, extremo norte da ilha (Fig. 8C). Os fragmentos estão geralmente cimentados por sílica ou óxidos/ hidróxidos de ferro, fazendo com que essas rochas se destaquem por erosão diferencial, devido a sua grande resistência mecânica. Por vezes, essas faixas de brechas/cataclasitos promovem a fragmentação de diques do Enxame Florianópolis (Fig. 8D), indicando tectonismo ou reativações tectônicas sin ou pósCretáceo. 
TOMAZZOLI, E.E \& PELLERIN, J.M. Unidades do mapa geológico da ilha...

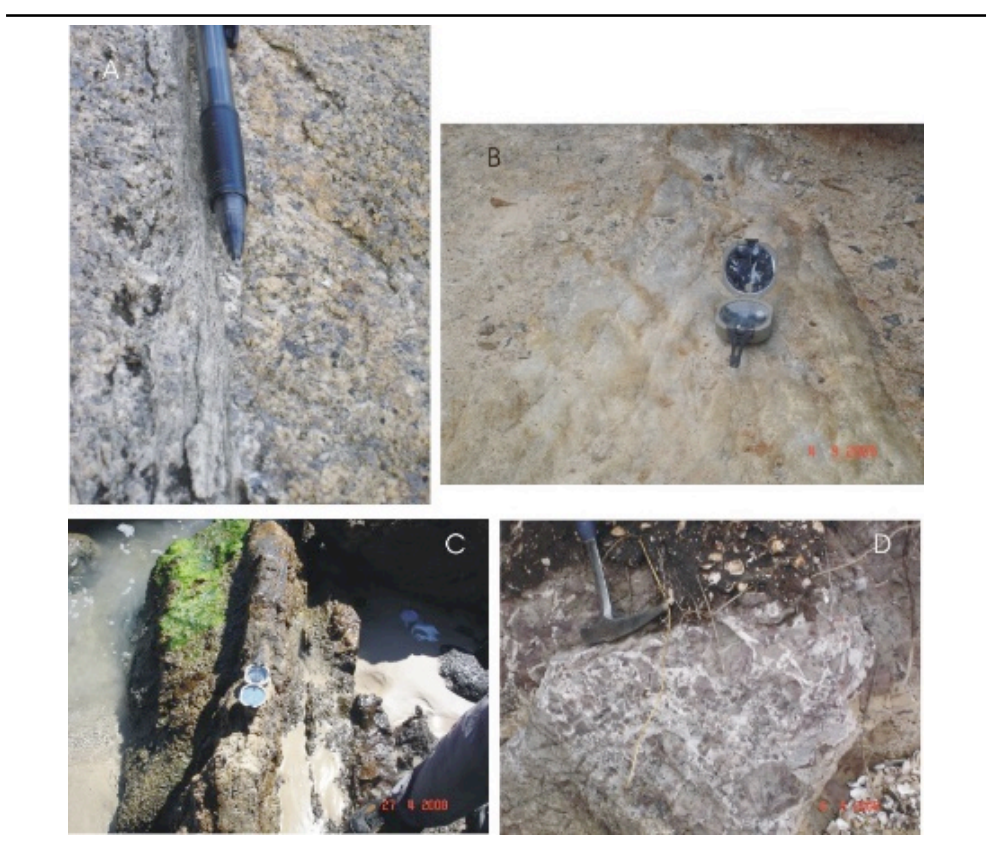

Figura 8: (A) Faixa de cisalhamento dúctil, com milonito, seccionando Granito Ilha. (B) Filito milonítico com foliação subvertical. (C) Faixa de cataclasitos e brechas de falha. (D) Brecha de diabásio de dique do Enxame Florianópolis, cimentada por sílica.

\section{Considerações finais}

$\mathrm{Na}$ ISC, os maciços rochosos são constituídos, predominantemente, pelo Granito Ilha, cujo carácter homogêneo, sem grandes variações, permite supor, num primeiro momento, uma baixa variabilidade litológica. Entretando, longe de ser monótona, a geologia da ISC é pautada por uma larga variabilidade, com múltiplos litotipos associados a pelo menos sete unidades geológicas pré-cambrianas e mesozóicas. Isso faz da ilha 
TOMAZZOLI, E.E \& PELLERIN, J.M. Unidades do mapa geológico da ilha...

um local particularmente intessante à pesquisa geológica em diferentes áreas, passivas de abordagens sob enfoques diversos.

\section{Referências bibliográficas}

BASEI, M.A.S. O cinturão Dom Feliciano em Santa Catarina. São Paulo. 185p. Tese de doutorado. Programa de Pós-graduação em Geociências. Universidade de São Paulo. 1985.

BITENCOURT et al. 2008

CARUSO JR., F. Mapa geológico da ilha de Santa Catarina Escala 1:100.000. Texto explicativo e mapa. Notas Técnicas, 6:1-28. 1993.

DIDIER, J. \& BARBARIN, B. (Eds.). Enclaves and granite Petrology. Developments in Petrology 13. Amsterdam: Elsevier, 625p. 1991.

FLORISBAL et al., 2014

HALLS, H.C. The importance and potential of mafic dyke swarms in studies of geodinamic processes. Geological Associations of Canada, 9(3). 1982.

HORN FILHO, N.O;; TOMAZZOLI, E.R.; PELLERIN, J.R.M. Unidades do mapa geológico da ilha de Santa Catarina: os depósitos quaternários. 2015. (no prelo).

LIVI, N. S. \& HORN FILHO, N.O. Geologia e geomorfologia da planície costeira da ilha de Santa Catarina, litoral Central do estado de Santa Catarina, Brasil, em base ao estudo dos depósitos quaternários. Cadernos Geográficos, 27: 9-35. 2011.

MARQUES, L. S. Geoquímica dos diques toleíticos da costa sulsudeste do Brasil: contribuição ao conhecimento da Província 
TOMAZZOLI, E.E \& PELLERIN, J.M. Unidades do mapa geológico da ilha...

Magmática do Paraná. São Paulo. Livre-Docência Thesis. Universidade de São Paulo. 2001.

PIMENTA, L.H.F. Aplicação de Sistema de Informação Geográfica para estudo da geodiversidade e valorização do geopatrimônio em Unidades de Conservação da Mata Atlântica. Florianópolis. Tese de doutorado. Programa de Pósgraduação em Geografia. Universidade Federal de Santa Catarina. (em preparação). 2015.

PITCHER, W.S. Synplutonic dykes and mafic enclaves. In: DIDIER, J.; BARBARIN, B. (Eds.) Enclaves and granite Petrology. Elsevier: Amsterdam, p. 383-391. 1991.

RAPOSO, M.I.B., ERNESTO, M., RENNE, P.R. Paleomagnetism and 40Ar/39Ar dating of the early Cretaceous Florianópolis dike swarm. Physics of the Earth and Planetary Interiors. Vol 108-4, p.275-290. 1998 .

SCHEIBE, L.F. \& TEIXEIRA, V.H. Mapa topogeológico da ilha de Santa Catarina. Porto Alegre. DNPM (inédito, sem texto explicativo). 1970.

SILVA, L.C.; HARTMANN, L.A.; MCNAUGHTON, N.J. \& FLETCHER, I.R. Zircon U/Pb SHRIMP dating of a Neoproterozoic overprint in Paleoproterozoic granitic gneissic terranes, southern Brazil. American Mineralogist, 85:649-667. 2000 .

TAYLOR, T.R., VOGEL, T.A-, WILBAND, J.T. The composite dikes at Mount Desert Island, Maine: an example of coexisting acid and basic magmas. Joun. Geol., 88:433-444. 1980.

TOMAZZOLI, E.R. Rochas ácidas associadas ao Enxame de Diques Florianópolis, Província Magmática Paraná. In: 45 
TOMAZZOLI, E.E \& PELLERIN, J.M. Unidades do mapa geológico da ilha...

CONGR. BRASILEIRO DE GEOLOGIA. Belém (PA). Anais...PAP003834. 2010. CD-ROM.

TOMAZZOLI, E.R. Enxame Florianópolis-Ilha de Santa Catarina. In: Projeto: "Tectônica rúptil meso-cenozoica e magmatismo associado: estudo integrado do embasamento adjacente à bacia de Santos, S-SE do Brasil". Convênio PETROBRAS e Universidade do Estado do Rio de Janeiro - UERJ. Convênio Específico $\mathrm{N}^{\mathrm{o}}$ 9. Termo de Cooperação $\mathrm{N}^{\mathrm{o}}$ 0050.0022710.06.4. (inédito). 2011.

TOMAZZOLI, E.R. Idade cretácica em granitoide na ilha de Santa Catarina (SC). In: $47^{\circ}$ CONGR. BRASILEIRO DE GEOLOGIA. Salvador (BA). CD dos trabalhos. Anais...PAP 015580. 2014. CDROM.

TOMAZZOLI, E.R., MIZUSAKI A. M.P., LIMA, E.F., FELIX, A.; FIGUEIREDO, A.M.G. Rochas ácidas associadas ao Enxame de Diques Florianópolis na ilha do Arvoredo e na ilha de Santa Catarina (SC): dados geocronológicos preliminares. In: III SIMP. DE VULCANISMO E AMBIENTES ASSOCIADOS. Cabo Frio (RJ). Anais... 2005. CD-ROM.

TOMAZZOLI, 2015 em preparação

TOMAZZOLI, E.R. \& LIMA, E.F. Magmatismo ácido-básico na ilha do Arvoredo-SC. Rev. Bras. Geociências, 36: 57-76. 2006.

TOMAZZOLI, E.R. \& PELLERIN, J.R.M. O Enxame de Diques Florianópolis na ilha de Santa Catarina (SC): mapa geológico. In: IV SIMPÓSIO DE VULCANISMO E AMBIENTES ASSOCIADOS, 2008, Foz do Iguaçu (PR). Anais...2008. CDROM. 
TOMAZZOLI, E.E \& PELLERIN, J.M. Unidades do mapa geológico da ilha...

TRAININI, D.R.; DIAS, A.A.; KREBS, A.S.J.; SOUZA, E.C.; CAPELETTI, I.; TONIOLO, J.A.; SILVA, L.C. \& SILVA, M.A.S. Projeto Vidal Ramos-Biguacu. Convênio DNPM/CPRM. (Relatório Interno). Porto Alegre, 303p. 1978.

VERNON, R.H. Microgranitoid enclaves in granites - globules of hybrid magma quenched in a plutonic environment. Nature, 309: 438-439. 1984

ZANINI, L.F.P.; BRANCO, P.M.; CAMOZZATO, E. \& RAMGRAB, G.E. (orgs.) Programa Levantamentos Geológicos Básicos do Brasil. Florianópolis (FolhaSH.22-Z-D-V) e Lagoa (Folha SH.22-Z-D-VI). CPRM, Brasília, 252p., mapas. Escala 1:100.000. 1997.

Recebido em maio de 2015 Aceito em novembro de 2015 